\title{
English Today and tomorrow
}

This is the 100th issue of English Today, and much of this issue is given over to a celebration of one hundred issues, and the stellar contribution of $E T$ 's founding editor Tom McArthur to not only the journal, but the whole field of English studies worldwide.

The editors particularly appreciate the tributes and comments that have come in from members of ET's editorial board, as well as from a wide range of academics and scholars engaged in the study and teaching of English linguistics and literature. The list of those moved to contribute their thoughts on this occasion includes John Algeo, Richard W. Bailey, Evelyn Ch'ien, David Crystal, Isagani R. Cruz, Daniel Davis, Azirah Hashim, Nobuyuki Honna, Braj B. Kachru, Yamuna Kachru, Andy Kirkpatrick, Gerry Knowles, Peter Lowenberg, Andrew Moody, Salikoko Mufwene, David Nunan, Pam Peters, Suzanne Romaine, Mario Saraceni, Edgar W. Schneider, Barbara Seidlhofer, Larry E. Smith, Loreto Todd, Katie Wales, and Catherine Walter. Some of those who wrote in have known Tom personally for many years, while others had come to know Tom only through his writing and through the journal, but, as editors, we were struck by the warmth and sincerity of all the tributes to Tom's work that came in. We are also sure that many others would have sent messages, had they known of this occasion. So many people in this field share not only very warm thoughts about Tom, but also a major debt of gratitude to him for his pioneering work in the study of English worldwide, as well as his encouragement of their own individual efforts. Through our work as researchers and editors, we are aware of how large the community of educators, linguists, and teachers in the field of contemporary English studies is, and how many in that community have been touched by Tom and his work. Like Tom, we share a fascination with the ongoing story of the spread of English as a world language. Like Tom, too, we are equally aware that this story has a number of facets, and that the dominance of English in many educational settings is often problematic and contested, and, whatever our fascination with the linguistic, social, and political dimensions of English as a global language, our approach to such issues must be tempered by a respect for the linguistic ecologies and multilingual diversity of the world. English may have the potential for empowerment, but also a potential for the reverse, as Tom himself has highlighted in a number of essays on the subject.

On this occasion, it is fitting to look back at the range and scope of ET during its first hundred issues, but perhaps it's also a good time to look forward. For the editorship of English Today, Tom has passed the torch on to us three, and we take the task of living up to Tom's standards and Tom's ethos very seriously. Tom McArthur will stay on the editorial masthead as 'Founding Editor', but it is really up to us now to keep ET's traditions going, as well as adding some innovations as we move forward. In this present issue, we include one new departure that we hope will become a regular feature, i.e. the new ET column, where we'll ask scholars in the field to contribute a column of topical interest. We'll also be reviving some features from the past, including book reviews (and many thanks to Philip Shaw for his review in this issue), as well as a 'Letters to the editors' section. Here, we would very much like the readers which means all you good folk reading this - to write in and give us your opinions about what it is you like or dislike about ET's current direction, what you think is good and what you think is bad, and what you think ET should be, as we move forward. We look forward to finding out more about who are readers actually are, whether they are academics, educators, journalists, students, or others, and what their interest in the continuing story of English is. So, if you are interested in writing to us, please don't hesitate to send us a message - long or short - to englishtoday@telkomsa.net_The Editors

The editorial policy of English Today is to provide a focus or forum for all sorts of news and opinion from around the world. The points of view of individual writers are as a consequence their own, and do not reflect the opinion of the editorial board. In addition, wherever feasible, ET generally leaves unchanged the orthography (normally British or American) and the usage of individual contributors, although the editorial style of the journal itself is that of Cambridge University Press. 